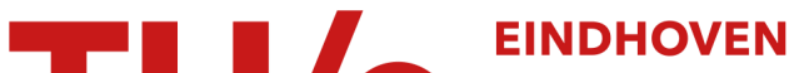 \\ UNIVERSITY OF \\ TECHNOLOGY
}

\section{Decision-making experiments and real-world choice behaviour}

Citation for published version (APA):

Timmermans, H. J. P., vd Heijden, R. E. C. M., \& Westerveld, J. (1984). Decision-making experiments and realworld choice behaviour. Geografiska Annaler B : Human Geography, 66B(1), 39-48.

https://doi.org/10.2307/490527

DOI:

$10.2307 / 490527$

Document status and date:

Published: 01/01/1984

\section{Document Version:}

Publisher's PDF, also known as Version of Record (includes final page, issue and volume numbers)

\section{Please check the document version of this publication:}

- A submitted manuscript is the version of the article upon submission and before peer-review. There can be important differences between the submitted version and the official published version of record. People interested in the research are advised to contact the author for the final version of the publication, or visit the $\mathrm{DOI}$ to the publisher's website.

- The final author version and the galley proof are versions of the publication after peer review.

- The final published version features the final layout of the paper including the volume, issue and page numbers.

Link to publication

\section{General rights}

Copyright and moral rights for the publications made accessible in the public portal are retained by the authors and/or other copyright owners and it is a condition of accessing publications that users recognise and abide by the legal requirements associated with these rights.

- Users may download and print one copy of any publication from the public portal for the purpose of private study or research.

- You may not further distribute the material or use it for any profit-making activity or commercial gain

- You may freely distribute the URL identifying the publication in the public portal.

If the publication is distributed under the terms of Article 25fa of the Dutch Copyright Act, indicated by the "Taverne" license above, please follow below link for the End User Agreement:

www.tue.nl/taverne

Take down policy

If you believe that this document breaches copyright please contact us at:

openaccess@tue.nl

providing details and we will investigate your claim. 


\title{
DECISION-MAKING EXPERIMENTS AND REAL-WORLD CHOICE BEHAVIOUR
}

\author{
BY \\ HARRY TIMMERMANS, ROB VAN DER HEYDEN AND HANS WESTERVELD*
}

\begin{abstract}
This article is concerned with the analysis of consumer spatial choice behaviour using conjoint measurements. The study's objectives are to assess the appropriateness of conjoint measurement to represent a consumer's spatial decision making process, to identify the nature of aggregate utility functions in the context of spatial shopping behaviour, to investigate whether systematic relationships can be found between the nature of the utility functions of the subjects and their sociocconomic background, and finally, to investigate whether utility values obtained under experimental conditions are systematically related to real world choice behaviour. The findings of the study suggest that conjoint measurement is a potentially useful approach to the study of consumer spatial decision-making. Conjoint measurement models provided a good description of individual decision making processes under experimental conditions and the inferred utility functions appeared to be systematically related to real world choice behaviour. The analysis also showed that subjects could be segmented on the basis of the nature of their utility function but no significant associations between the segmentations and a set of socio-economic background variables were found. The article ends with a discussion of some unresolved questions in the application of conjoint measurement in spatial analysis.
\end{abstract}

\section{Introduction}

The modelling of how individuals choose among multi-attribute spatial alternatives has been of increasing interest to geographers. During the last decade an ever increasing number of studies has been concerned with predicting the probability that an individual will choose a particular alternative from among all possible alternatives, given the location of the individual and the locations and characteristics of the (v alternatives. Prior studies have adopted a variety of model structures to tackle this research problem in the context of spatial shopping behaviour. For example, some researchers have used the revealed preference approach (Rushton, 1969b; Girt, 1976; Timmermans. 1981), which attempts

\footnotetext{
${ }^{*}$ Dr. H. Timmermans, Ir. R. van der Heyden and Ir. H. Westerveld, Dept. of Architecture, Building and Planning, University of Technology, P.O. Box 513, H.G. 11.25, 5600 MB Eindhoven, The Netherlands.
}

first to derive preference structures by scaling a similarity matrix of locational types and subsequently, relates these preference structures to overt choice probabilities by some mathematical function or decision rule. Other researchers have tried to relate overt choice probabilities directly to a set of independent variables, mostly defined as a set of attractiveness terms and a distance variable, using either a spatial interaction or a logit specification (e.g. Smith et al, 1977; Recker and Kostyniuk, 1978).

Although clear differences exist between these various approaches, they all have in common that the functional form of the utility expression in the model is inferred from data on observed spatial choice behaviour. However, it is this very idea that has been criticised by a number of authors (e.g. Rushton, 1969a; MacLennan and Williams, 1979, 1980). Consequently, more recently scholars have shown increased concern for determining the way in which consumers form preferences in laboratory experiments. Axiomatic utility theory, functional measurement and conjoint measurement have been used to recapture the nature of the process whereby individuals cognitively combine part-worth utilities to arrive at a choice or a preference ordering (e.g. Louviere, 1976, 1979, 1981; Louviere and Meyer, 1979; Louviere and Wilson, 1978: Lieber, 1979; Schuler, 1979; Schuler and Prosperi, 1978; Timmermans, 1980, 1982).

Although results obtained thus far have been promising, more empirical analyses are necessary however to assess more adequately the applicability of these approaches in the study of spatial choice behaviour.

The purpose of this article is to address this issue. It reports on a number of empirical analyses conducted to assess the applicability of conjoint measurement in the study of spatial shopping behaviour. The study is part of a wider research project which attempts to develop predictive models of consumer choice behaviour on the basis of judgements obtained in experimental conditions. 


\section{Research questions}

The objective of the study can be stated in terms of a number of research questions which guided the study design and the analyses.

1. How well does an additive/a multiplicative conjoint measurement model represent an individual's decision-making process in a laboratory experiment?

2. What is the nature of the aggregate utility function?

3. Can individual differences in subjects' utility functions be distinguished and what is the nature of the aggregate utility functions of resulting subgroups of subjects?

4. Do subjects who evidence similarities in their utility function also show similarities in terms of their socio-economic background?

5. Are individuals' overall utility values obtained in experimental settings using conjoint measurements systematically related to their real-world choice behaviour?

6. Do subjects who differ in terms of the relative importance they attach to the various attributes of a multi-attribute stimulus also differ in terms of their real-world choice behaviour?

These research questions will be addressed in the second part of this article. However, because a detailed account of conjoint measurement models is lacking in the geographical literature, first an introduction to conjoint measurement analyses will be presented in the next section.

\section{Conjoint measurement}

Assume that an attempt is being made to measure an individual's overall utility for a multiattribute alternative. Assume further that individuals view the alternatives in terms of a bundle of attributes and that they arrive at a measure of overall utility by a process whereby they cognitively integrate the part-worth utilities, defined on the attribute levels, according to some algebraic rule. How can we measure the overall utility for the alternative? One way to proceed would be to ask the subjects to provide some measure of utility for each attribute compromising the choice alternative and then calculating overall utility by, for example, summing these partworth utilities. The difficulty of this procedure however is that it might be impossible for the subjects to express their part-worth utilities and hence any attempt to measure overall utility by directly measuring and summing part-worth utilities could result in high measurement error.

Conjoint measurement is based on the notion that it may still be possible to measure the relative contributions of two or more independent variables, even though their individual effects may not be measurable properly in any direct fashion. This is typically accomplished by asking subjects to rank order choice alternatives with respect to their overall utility. Next the partworth utilities are derived given some a priori specified composition rule, which describes, in mathematical terms, the way in which subjects combine these part-worth utilities to arrive at an overall utility measure. This measurement problem is known as the conjoint measurement problem and the rule which specifies the composition of the part-worth utilities of attribute levels is called the conjoint measurement model (Luce and Tukey, 1964; Krantz, 1964). The various approaches to this problem differ in terms of the specification of the measurement model, the research design used to derive the part-worth utilities and parameter estimation methods.

Conjoint measurement is thus concerned with simultaneously measuring the joint effect of two or more independent variables on the rank ordering of a dependent variable. In its most commonly used form it provides a model in which part-worth utilities for various attributes of multi-attribute alternatives can be estimated from subjects' preference orderings of a set of factorially designed alternatives. Initially much effort has been spent on the axiomatization of the necessary conditions for applying various composition rules (e.g. Krantz, 1964; Tversky, 1967; Krantz and Tversky, 1971; Barron, 1977; Emery and Barron, 1979). More recently however the focus has been on the derivation of the part-worth utility scales. Usually part-worth utilities of the attributes are derived such that the rank ordering of the choice alternatives as predicted by a prespecified measurement model is as nearly monotonic with the expressed rank ordering of the choice alternatives as possible. The goodness of fit of the scaling solution is indicated by a measure called 'stress' which is for the three attributes case defined as:

$$
S=\sqrt{\frac{\sum_{j k 1} \sum\left(z_{j k l}-\hat{z}_{j k l}\right)^{2}}{\sum_{j k 1} \sum_{j k l} n_{j k l}\left(z_{j k l}-\bar{z}\right)^{2}}}
$$


where:

$\hat{\mathrm{z}}_{\mathrm{jkl}}=$ the monotonic regression value which best predicts $z_{\mathrm{jk}}$ from the rank orders

$\mathrm{z}_{\mathrm{jkl}}=$ the corresponding value derived from the specified measurement model

$\mathbf{n}_{\mathrm{jkl}}=$ the number of observations for combination $\mathrm{j}, \mathrm{k}, \mathrm{l}$

and

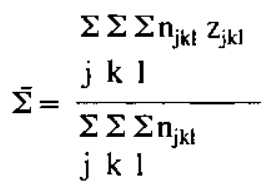

Most computer algorithms adopt the steepest descent method to minimise S. Several measurement models may be used as representations of the preference data (Timmermans, 1980). In the present paper only the additive and the multiplicative model will be considered. Let $\mathrm{u}\left(\mathrm{x}_{\mathrm{ij}}\right)$ denote the part-worth utility for attribute $i$ and let $u(X)$ denote the overal utility of a choice alternative $j$, then the additive conjoint measurement model can be expressed as:

$$
u(X)=\sum_{i=1}^{m} u\left(x_{i j}\right)
$$

whereas the multiplicative conjoint measurement model is given by:

$$
u(X)=\prod_{i=1}^{m} u\left(x_{i j}\right)
$$

where $m$ is the total number of attributes. Although originally the nonmetric approach to parameter estimation described above has been employed most frequently, more recently alternative estimation methods have been used. For ": example, some authors have assumed that the subject's rank orderings are measured at an interval scale. By assuming an intervally scaled dependent variable it is possible to use ordinary least squares regression to estimate the parameters of the conjoint measurement model. This procedure has the advantage that standard errors for the estimated parameters are provided. On the other hand, the assumption of interval scale properties of the rank ordering might be questionable in some cases. Other authors have advocated the use of probability models such as logit and probit models to parameterise the conjoint measurement model. Such approaches explicitly model the errors which might be present in the utility function. Finally, Srinivasan and Shocker (1973a, 1973b) have advanced the use of linear programming techniques to estimate the parameters of a conjoint measurement model. Their approach has the advantage that it guarantees global optimum parameter estimates and that constraints can be imposed on these estimates.

As has been indicated above, in most applications of conjoint measurements the choice alternatives are designed according to a factorial design. One of the problems that a researcher encounters using this design is that any complex decision-making task yields an unreasonable large number of choice alternatives. For example, if it is assumed that each choice alternative is to be defined by 6 attributes and that each attribute has three levels $3^{6}=729$ combinations are generated. Clearly, this constitutes an unrealistic ranking task for the subjects. Hence, alternate designs have been suggested. Johnson (1974), for example, advocated the use of a paired comparison design, whereas Green (1974) has suggested the use of various types of fractional factorial designs. A disadvantage of the most efficient fractional factorials is however that only additive models can be tested.

Given these various models, estimation methods and designs it might be concluded that the conjoint measurement approach constitutes a very flexible approach to measure individual utility functions in a variety of contexts.

\section{Study design}

The empirical analysis to assess the applicability of conjoint measurements in the study of spatial consumer behaviour was conducted in the district of Woensel in the city of Eindhoven. This area has 13 shopping centres which vary considerably in terms of their size, age and layout characteristics. The data for the analysis were gathered in the summer of 1980 from a sample of 91 housewives. All interviews were administrated on a personal basis by trained interviewers. The sample was diverse in terms of the socioeconomic and demographic characteristics of the respondents.

The interviewers collected a variety of data from the respondents, but for the following analysis only some data are particularly relevant. Specifically the data base consisted of the following matrices: 
1. A $91 \times 13$ matrix describing the shopping behaviour of the respondents.

2. A $91 \times 27$ matrix of respondents' rankings of 27 hypothetical shopping centres, each describing a three attribute profile.

3. A $91 \times 4$ matrix of respondent socio-economic variables.

4. A $91 \times 13$ matrix of each respondent's overall evaluation of the 13 shopping centres.

All respondents were told by the interviewers that the purpose of the interview was to gain insight into the respondent's decision-making process in the context of buying durable goods. The data were collected on the basis of the following procedures and tasks.

The data on spatial shopping behaviour were collected in a straightforward manner. Each respondent was asked to mention which shopping centres she patronizes in order to buy durable goods. In addition, each respondent was invited to state the frequency of her visits to each of the thirteen shopping centres in the study area. The information thus collected resulted in the $91 \times 13$ matrix describing the shopping behaviour of the respondents. The conjoint measurements involved several operational decisions regarding the selection of the attributes of the hypothetical choice alternatives, the way to present the stimuli and the estimation method. The stimuli of the conjoint measurement experiment consisted of 27 hypothetical shopping centres, each describing a three attribute profile. The attributes of the choice alternatives were selected on the basis of an exploratory research project which attempted to identify the factors influencing destination choice behaviour. This study used a separate sample of 20 respondents. The repertory grid methodology was employed to elicit the influential factors. The results of the study were validated using the factor listing approach for 192 respondents. Both studies suggested that size, distance and parking facilities were the most important factors in influencing consumer decision-making in the context of buying durable goods. The reader is referred to Timmermans, van der Heyden and Westerveld (1982) for further details. Given these results, the number of shops, distance and parking were selected as the attributes which define the hypothetical shopping centres. Each attribute was varied over three levels: number of shops varied over small, medium and large number of shops, distance va- ried over 15,30 and 45 minutes and parking varied over 4,12 and 20 minutes search time to find a free parking lot. The levels of the three attributes were combined into a $3 \times 3 \times 3$ factorial design to yield 27 hypothetical shopping centres. Each three attribute profile was printed on an index card. Each respondent was requested first to sort the index cards into three ordered categories of preference and then to rank the index cards within each category from most preferred to least preferred. Finally, each respondent was asked to ascertain that the resulting rank ordering of the 27 stimuli was correct. Otherwise shifting cards across categories was allowed. All cards were randomised prior to presentation to a respondent. This procedure thus resulted in a strict rank ordering of the hypothetical shopping centres for each respondent. Each rank ordering was submitted separately to the UNICON algorithm (Roskam, 1974). This program contains a nonmetric version of estimating the parameters of the conjoint measurement model.

As to the socio-economic variables, data on four types of variables were collected, viz. car use, education, length of residence and age. linally data were collected on respondents' evaluations of the thirteen shopping centres in the study area. Each respondent was asked to express her overall evaluation for each shopping centre on a $\mathrm{I}-100 \mathrm{~mm}$ rating scale ranging from extremely bad to excellent. Each respondent was first asked to examine all thirteen shopping centres and to assign a rating value to the most preferred shopping centre. Next, each respondent was asked to provide ratings for the remaining twelve shopping centres relative to the rating of the most preferred shopping centre. In the case that a respondent did not possess any knowledge about a particular shopping centre, she was asked not to provide a score for this shopping centre in order to avoid measurement bias. The procedure resulted in a $91 \times 13$ matrix of respondents' evaluation scores of the shopping centres.

\section{Analysis and results}

The appropriateness of the measurements models

The first step in the analysis was to apply both the additive and the multiplicative model to each respondent's rank ordering of the hypothetical shopping centres. The appropriateness of these models was judged on the basis of stress levels, 
and the monotonicity of the derived part-worth utility scores in a priori hypothesized directions. In addition, the validity of this measurement procedure was assessed by computing Spearman rank correlation coefficients and Pearson product moment correlation coefficients between the derived overall utility value and the expressed overall evaluation score for each of the thirteen shopping centres. The details of these analyses appear elsewhere (Timmermans, van der Heyden and Westerveld, 1983). The results of the analyses suggest that the conjoint measurement models can be applied successfully to describe the way in which respondents form overall utilities from their part-worth utilities. The additive conjoint measurement model performed best for 32 respondents whereas the multiplicative conjoint measurement model was most successful for the remaining 59 respondents. All respondents exhibited acceptably low stress values. The highest stress value is 0.020 , the average stress value is only 0.004 . All part-worth utilities for all respondents were monotonic in a priori hypothesized directions. That is, the results of the analysis showed that the part-worth utilities invariably increase with increases in the number of shops and parking availability and decrease with increases in the distance to the shopping centre. The external validity of the measurement procedure was also satisfactory as indicated by the fact that only 6 respondents exhibited rank correlation coefficients of lower than .4 .

\section{The nature of the aggregate utility fiuction}

Having derived the part-worth utility scales the next step in the analysis involved identifying the nature of the aggregate additive utility function. This was accomplished by computing average scale values of the data and then performing a ratio scale transformation. The derived aggregate utility function can be expressed as:

- $\mathrm{u}(\mathrm{X})=0.415$ (number of shops) +0.237 (parking facilities) +0.348 (distance)

This result indicates that the number of shops is the most important attribute at the aggregate level, wheras parking facilities is the least important attribute.

\section{Segmentation}

The following step in the analysis referred to the question of whether different segments can be identified in the sample on the basis of the nature of the conjoint measurement model and the values of the part-worth utilities defined on the levels of the attributes. Given a particular conjoint measurement model respondents' partworth utility values were used as input to identify clusters of respondents with similar part-worth utility values. Ward's criterion was used to define the clusters. This implies that at each successive stage of the hierarchical clustering process those clusters are merged that result in a minimum increase in the sum of the within group variances. This process was repeated twice, once for the respondents whose ranking profile was described best by the additive model and once for the respondents whose rank ordering was represented most successfully by the multiplicative model.

The successive stages of the clustering process are graphically portrayed in figures 1 and 2 for the additive and multiplicative models respectively. On the basis of an inspection of these dendrograms four clusters were identified: two (A and $B$ ) pertaining to the respondents who used the additive model and two (C and D) pertaining to the respondents whose rank ordering was most successfully described by the multiplicative model. Clusters A and B contain 21 and 11 respondents respectively whereas cluster $C$ and D are composed of 25 and 34 respondents respectively. Again, the relative importance of the three attributes was calculated for each cluster of respondents separately. The results are given in Table 1. Table 1 clearly indicates that size is the most important variable for the respondents of clusters B and D. More specifically, the size attribute accounts for 58 and 54 percent of the total variation in the scale weight for clusters D and $B$ respectively. The attribute distance accounts for 45 percent of the total variation in the scale weights in cluster $\mathrm{C}$, whereas this attribute accounts for 67 percent of the total variation of part-worth utilities in cluster $A$. The relative importance of the parking attribute also differs between the various clusters. It is relatively high for clusters $C$ and B, 31 and 29 percent respectively, and relatively low for clusters $A$ and $D$ with respectively 11 and 17 percent.

\section{Relationships with socio-economic rariables}

The analysis conducted thus far has resulted in two different classifications of the respondents. 


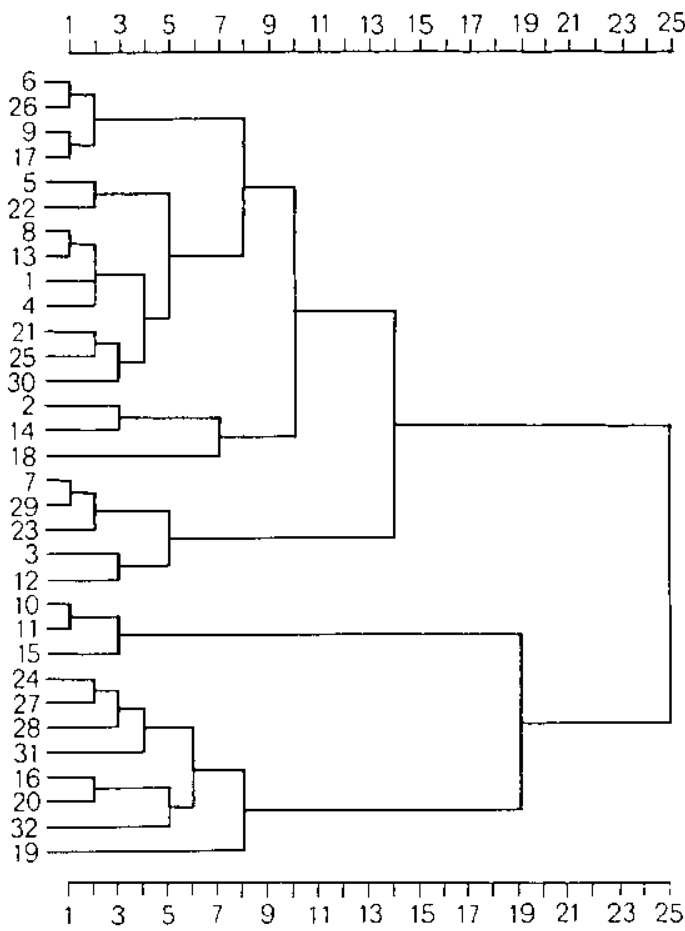

Fig. 1. The results of the clustering process for the additive model.

The first classification divides the respondents into two groups on the basis of whether an additive or a multiplicative model forms the best representation of a respondent's rank ordering of the 27 hypothetical shopping centres. In addition, the respondents may be classified on the basis of the relative importance they attach to the three attributes. Again, two groups may be identified. One group of respondents, consisting of clusters B and D, apparantly consider size to be the most important attribute, the remaining respondents attach the highest importance score to the distance attribute.

Given these individual differences the next step in the analysis concerned an examination whether these differences are systematically related to the socioeconomic characteristics of the respondents. Loglinear models were used to test this relationship. Loglinear models provide an efficient approach to test for associations in multidimensional contingency tables. To illustrate the use of loglinear models for this research question first consider the saturated loglinear

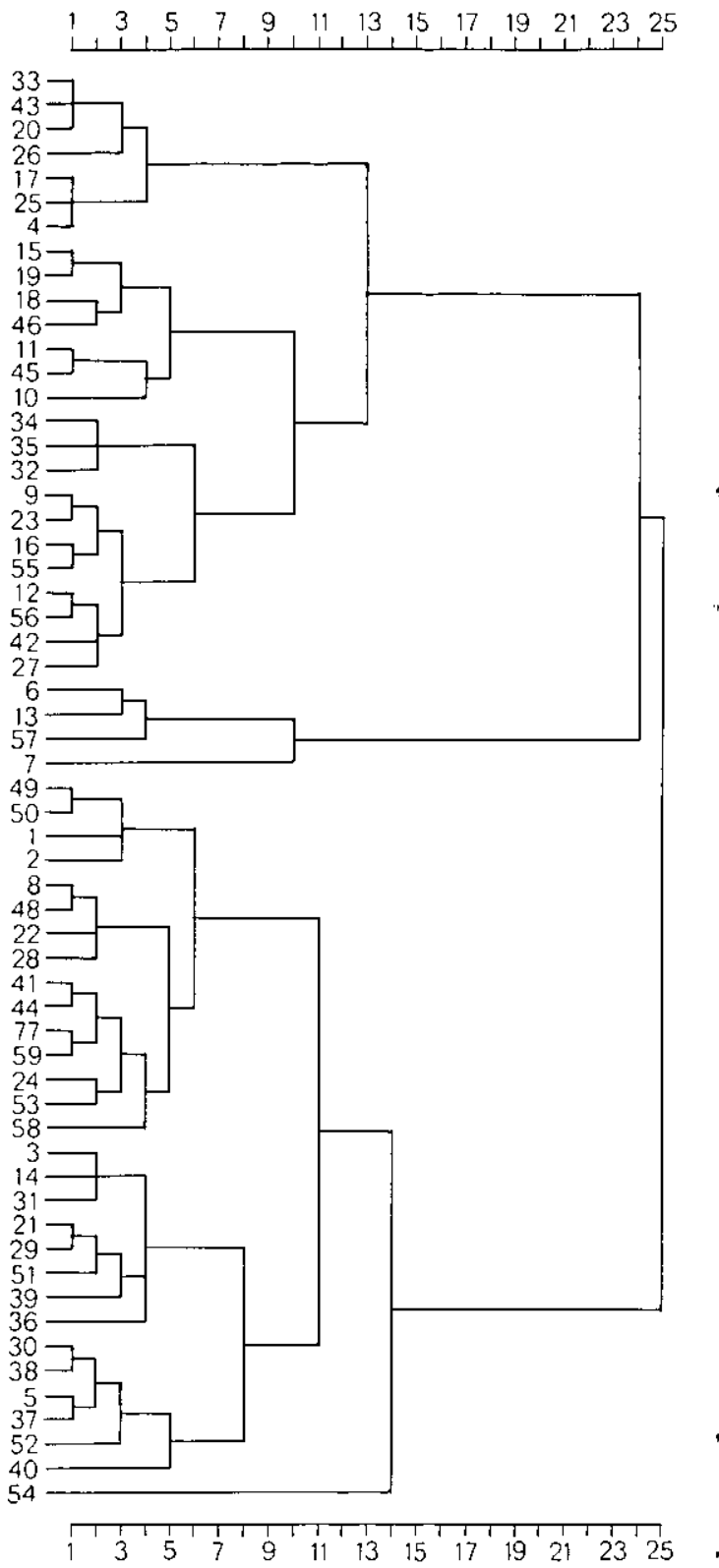

Fig. 2. The results of the clustering process for the multiplicative model.

model for a three dimensional contingency table. This model can be expressed as:

$$
\begin{aligned}
& \log _{\mathrm{e}} \mathrm{F}_{\mathrm{ij}}=\mathrm{u}+\mathrm{u}_{1(\mathrm{i})}+\mathrm{u}_{2(\mathrm{j})}+\mathrm{u}_{3(\mathrm{k})}+\mathrm{u}_{12(\mathrm{ij})}+ \\
& \mathrm{u}_{\mathrm{t3}(\mathrm{ik})}+\mathrm{u}_{23(\mathrm{jk})}+\mathrm{u}_{123(\mathrm{j} \mathrm{k})}
\end{aligned}
$$


Table 1. The relative importance of each attribute for each cluster of respondents.

\begin{tabular}{llll}
\hline Clusters & \multicolumn{2}{l}{ Attributes } & \\
\cline { 2 - 4 } & size & parking & distance \\
\hline A & 0.22 & 0.11 & 0.67 \\
B & 0.54 & 0.29 & 0.17 \\
C & 0.25 & 0.31 & 0.45 \\
D & 0.58 & 0.17 & 0.25 \\
\hline
\end{tabular}

where:

$$
\begin{aligned}
& u=\frac{\sum_{i=1}^{r} \sum_{j=1}^{c} \sum_{k=1}^{1} \log _{e} F_{i j k}}{r c 1} \\
& \mathrm{u}_{\mathrm{l}(\mathrm{i})}=\frac{\sum_{\mathrm{j}=1}^{\mathrm{c}} \sum_{\mathrm{k}=1}^{1} \log _{\mathrm{e}} \mathrm{F}_{\mathrm{ijk}}}{\mathrm{c} 1}- \\
& \sum_{i=1}^{r} \sum_{j=1}^{c} \sum_{r=1}^{1} \log _{e} F_{i j k} \\
& \mathrm{rcl} \\
& \mathrm{u}_{2(\mathrm{j})}=\frac{\sum_{\mathrm{i}=1}^{\mathrm{r}} \sum_{\mathrm{k}=1}^{1} \log _{\mathrm{e}} \mathrm{F}_{\mathrm{ijk}}}{\mathbf{r l}}- \\
& \frac{\sum_{i=1}^{r} \sum_{j=1}^{c} \sum_{r=1}^{1} \log _{e} F_{i j k}}{r^{c} \text { c l }} \\
& u_{23(j k)}=\frac{\sum_{i=1}^{r} \log _{e} F_{i j k}}{r}- \\
& \frac{\sum_{\mathrm{i}=1}^{\mathrm{r}} \sum_{\mathrm{k}=1}^{\mathrm{l}} \log _{\mathrm{e}} \mathrm{F}_{\mathrm{ijk}}}{\mathrm{rl}}- \\
& \frac{\sum_{i=1}^{r} \sum_{j=1}^{c} \log _{e} F_{i j k}}{r c}+ \\
& \frac{\sum_{i=1}^{r} \sum_{j=1}^{c} \sum_{k=1}^{1} \log _{e} F_{i j k}}{r \text { c l }}
\end{aligned}
$$

and the remaining terms are defined in a similar fashion.

Note that equation (4) specifies a linear model for the natural logarithms of the frequencies $\left(F_{i j k}\right)$. The logs of the frequencies are modelled as the sum of an overall effect (u), main effects $\left(u_{1(i)}, u_{2(j)}, u_{3(k)}\right)$ and a set of interaction effects. For the present analysis the interaction effects are particularly interesting since they identify those categories responsible for any departure from independence. That is, if all interaction effects are statistically insignificant beyond some significance level the model suggests that the variables constituting the contingency table are mutually independent. Similarly, significant interaction effects point at associations between the corresponding variables. In the case that the multidimensional contingency table contains an explicity defined dependent variable as well as a set of independent variables one should perform a logit transformation of the observed proportions in the contingency table. It can be proven that loglinear models yield identical parameter estimates to those that would be obtained from fitting logit models directly providing that all higher and implied lower interaction terms among the independent variables are included in the loglinear model.

To test whether car usage, education, length of residence and age were systematically related to the nature of the composition rule which has been used by a respondent to form a preference ranking, all these variables were held at the two-group level. This resulted in a $2 \times 2 \times 2 \times 2 \times 2$ contigency table of 32 cells. The socio-economic variables were treated as independent variables. The following loglinear model was used to study the associations within this table:

$$
\begin{aligned}
& \log _{\mathrm{e}} \mathrm{F}_{\mathrm{ijkl}}=\mathrm{u}+\mathrm{u}_{1(\mathrm{i})}+\mathrm{u}_{2(\mathrm{j})}+\mathrm{u}_{3(\mathrm{k})}+\mathrm{u}_{4(\mathrm{l})}+\mathrm{u}_{5(\mathrm{~m})}+ \\
& \mathrm{u}_{12(\mathrm{ij})}+\mathrm{u}_{13(\mathrm{ik})}+\mathrm{u}_{14(\mathrm{il})}+\mathrm{u}_{15(\mathrm{im})}+\mathrm{u}_{123(\mathrm{ijk})}+\mathrm{u}_{124(\mathrm{ijl})} \\
& +\mathrm{u}_{125(\mathrm{ijm})}+\mathrm{u}_{134(\mathrm{ikl})}+\mathrm{u}_{135(\mathrm{ikm})}+\mathrm{u}_{145(\mathrm{ilm})}+\mathrm{u}_{1234(\mathrm{ijk} \mathrm{j})} \\
& +u_{1235(i j k m)}+u_{1245(\mathrm{j} l m)}+u_{1345(i \mathrm{klm})}+\mathbf{u}_{12345(\mathrm{ijk} k \mathrm{~m})}+ \\
& \text { all implied lower order terms (2) }
\end{aligned}
$$

The values for the relevant parameter estimates as well as their standardised values are given in Table 2. This table shows that none of the interaction effects is significant at the 5 percent probability level. This finding suggests that none of the socio-economic variables nor some combination of these variables is associated with the use of either a multiplicative or an additive conjoint measurement model. 
Table 2. Parameter estimates and standardised values of a loglinear model expressing the effects of four socio-economic variables on the nature of the conjoint measurement model.

\begin{tabular}{|c|c|c|}
\hline Interaction terms & Effect & Standardised value \\
\hline$u_{12(U)}$ & 0.201 & 0.981 \\
\hline $\mathrm{U}_{13(1 \mathbf{k})}$ & -0.037 & -0.181 \\
\hline $\mathrm{u}_{14(1)}$ & -0.087 & -0.423 \\
\hline $\mathrm{u}_{1 \mathrm{~s}(\mathrm{Im})}$ & -0.066 & -0.324 \\
\hline $\mathrm{u}_{123(1) \mathrm{k})}$ & -0.037 & -0.181 \\
\hline$u_{12 k(t) t)}$ & -0.087 & -0.423 \\
\hline$u_{12 S(t) m}$ & -0.066 & -0.324 \\
\hline$U_{134(k))}$ & -0.050 & -0.244 \\
\hline $\mathrm{U}_{133(\mathrm{~km})}$ & 0.034 & 0.167 \\
\hline $\mathrm{U}_{145(11 m)}$ & -0.092 & -0.448 \\
\hline $\mathrm{U}_{1234(\mathrm{~J}) \mathrm{k}\}}$ & -0.050 & -0.244 \\
\hline $\mathrm{U}_{1235(\mathrm{ljkm})}$ & 0.034 & 0.167 \\
\hline$\left.U_{124(L)}(u) n\right)$ & -0.092 & -0.448 \\
\hline $\mathrm{U}_{\mathrm{i343}(\mathrm{k} / \mathrm{k})}$ & 0.009 & 0.043 \\
\hline $\mathrm{U}_{12345(1) \mathrm{k}) \mathrm{m} \text { ) }}$ & 0.009 & 0.043 \\
\hline
\end{tabular}

variable 1 = additive vs multiplicative rule variable 2 = level of education variable 3 = length of residence variable $4=$ age of respondent variable $5=$ car use
Table 3. Parameter estimates and standardised values of a loglinear model expressing the effects of four socio-economic variables on the importance attached to size vs distance.

\begin{tabular}{|c|c|c|}
\hline Interaction terms & Effect & Standardised values \\
\hline $\mathrm{U}_{12(\mathrm{U})}$ & 0.238 & 1.156 \\
\hline$u_{19(1 k)}$ & 0.000 & 0.000 \\
\hline $\mathrm{u}_{14(1)}$ & -0.098 & -0.474 \\
\hline $\mathrm{u}_{1 \mathrm{BS}(\mathrm{m})}$ & -0.135 & -0.656 \\
\hline $\mathrm{U}_{123(\{\mathrm{k})}$ & 0.000 & 0.000 \\
\hline $\mathrm{U}_{12 \&(1 \mathrm{~J})}$ & -0.098 & -0.474 \\
\hline $\mathrm{u}_{125(\mathrm{i} / \mathrm{m})}$ & -0.135 & -0.656 \\
\hline $\mathrm{u}_{134(\mathbf{k} \mathrm{k})}$ & -0.061 & -0.295 \\
\hline $\mathrm{u}_{135(\mathrm{k} \mathbf{k m})}$ & 0.103 & 0.499 \\
\hline $\mathrm{U}_{145(1 \mathrm{Im})}$ & -0.074 & -0.361 \\
\hline $\mathrm{u}_{123 *(1 j k)}$ & -0.061 & -0.295 \\
\hline $\mathrm{U}_{1235(1 \mathrm{j} / \mathrm{km})}$ & 0.103 & 0.499 \\
\hline $\mathrm{U}_{1245 \mathrm{ij} / \mathrm{tm} /}$ & -0.071 & -0.361 \\
\hline $\mathbf{U}_{1345}(\mathbf{k} ! \mathrm{m})$ & -0.111 & -0.539 \\
\hline $\mathrm{u}_{12345(\mathrm{IJk} / \mathrm{m})}$ & -0.111 & -0.539 \\
\hline
\end{tabular}

variable $\mathrm{i}=$ size most important vs distance most important variable $j=$ level of education variable $\mathrm{k}=$ length of residence variable 1 = age of respondent variable $m=$ car use

This procedure resulted in an overall utility estimate for each shopping centre about which a respondent possesses knowledge.

Spearman's rank correlation coefficients were calculated as a measure of the strength of the relationship between the derived utilities of the 13 shopping centres and a respondent's frequency of patronising these centres. The results of this analysis are shown in Table 4. This table indicates that the findings are satisfactory. A total of 66 out of 91 respondents exhibit a rank correlation coefficient of at least. 4 . On the other hand, 11 respondents evidence a negative rank correlation coefficient. It is not readily evident why these negative correlations occur. However, it might be that these respondents use still different attributes to choose a particular shopping centre. Or, their subjective evaluation of the shopping centres might depart markedly from the average evaluation of these shopping centres. Another explanation might be that they provided invalid preference rankings of the hypothetical shopping centres. In general though, Table 4 demonstrates that the utility scores obtained under experimental conditions are systematically related to real world choice behaviour, at least in the context of shopping of durable goods. 
Table 4. Frequency distribution of Spearman's rank correlation coefficients between derived utility scales and overt choice behaviour.

\begin{tabular}{lcc}
\hline Value & $\begin{array}{l}\text { Number of } \\
\text { respondents }\end{array}$ & $\begin{array}{l}\text { Percentage of } \\
\text { total sample }\end{array}$ \\
\hline $0.8-1.0$ & 46 & 50.5 \\
$0.6-0.8$ & 8 & 8.8 \\
$0.4-0.6$ & 12 & 13.2 \\
$0.2-0.4$ & 4 & 4.4 \\
$0.0-0.2$ & 10 & 11.0 \\
$<0.0$ & 11 & 12.1 \\
\hline Total & $\mathrm{N}=9 \mathrm{I}$ & 100.0 \\
\hline
\end{tabular}

\section{Conclusions and discussion}

The main thrust of the present study has been to conduct a number of empirical analyses to gain more insight into the potentials of conjoint measurement models to uncover the nature of decision-making processes in the context of spatial shopping behaviour. In particular, this study has sought to assess the validity of the additive and the multiplicative conjoint measurement model, to demonstrate that utility expressions obtained in hypothetical settings are related to overt choice behaviour and to test for possible associative variables and segmentations.

The findings of this study generally suggest that the described methods of analysis provide a potentially useful approach to the understanding of consumer decision-making. The results of the study indicate that the conjoint measurement models provide good descriptions of the rank orderings of the respondents. In addition, the results obtained from the conjoint measurements were proven to be reasonably related to direct ratings of real-world shopping centres in a linear fashion. Further, the analyses suggest that the utility functions as inferred from the rank ordering of the hypothetical shopping centres are systematically related to real-world observed choice behaviour. Finally, the analyses have indicated that the respondents could be segmented on the basis of the form of their utility function as well as on the basis of the relative importances they attach to the various attributes of the multiattribute choice alternatives. However, no significant associations were found between these segmentations and a set of socio-economic measurements obtained from the same respondents.
Although the research findings generally support the approach a number of unresolved questions deserve further attention. Firstly, the presented study has only considered three attributes. If however a hypothetical choice alternative needs to be defined in terms of more than three attributes in order to constitute a realistic description of real world alternatives the factorial design as adopted in this study is difficult to employ. Hence, a researcher might wish to use for example a paired comparison design to infer the utility function. However, such a design assumes that a respondent can provide judgements about pairs of attributes independently of the categories of the other attributes. In addition, when providing quite a large number of preference orderings a respondent might tend to use patternized types of responses. Thus, one line of further research would be to investigate whether this and other designs can be employed successfully to derive utility functions for more complex decision-making tasks.

Secondly, it must be evident that the present study has considered only two conjoint measurement models. Future research could be directed at comparing the predictive ability of these model structures with that of competing models. In particular, non-compensatory models, which assume that an individual evaluates multiattribute choice alternatives on some attribute-by-attribute basis rather than in some compensatory manner, deserve further investigation in this respect.

Thirdly, an attractive feature of conjoint measurement as adopted in this study is that a respondent only is required to provide a rank ordering of a set of choice alternatives. However, while this task can be considered as rather easy for the respondent it requires, strictly speaking, the use of nonmetric conjoint measurement analysis to estimate the parameters of the hypothesized utility function with the disadvantage of having no estimates of the standard errors of the parameters. Alternatively, one could obtain rating scale measures instead of preference rank orderings, which might be a more difficult task for the respondent, or one could apply ordinary regression methods to preference orderings to estimate the parameters of a conjoint measurement model.

Hence, it seems that we encounter a situation of trade-off between the difficulty of a respondent's evaluation task and the advantages of 
various methods of parameter estimation. Therefore it seems worthwhile to investigate the robustness of regression methods and the validity of rating vis-a-vis ranking tasks.

Finally, while conjoint measurements might yield valuable insights in how consumers form preferences for multiattribute choice alternatives, the ultimate aim of a behavioural analysis of spatial consumer behaviour will be to predict their real world choice behaviour. Hence, a next step in the approach would be to include the utility function as derived under laboratory conditions in a predictive model of consumer choice behaviour. Future research should address the issue which decision rules and multivariate probability distributions can be employed most successfully to predict the probability that a consumer will select a particular shopping centre from a set of all possible shopping centres given his/her evaluations of these shopping centres. If these issues can be resolved it seems that conjoint measurement models provide a still more powerful, if limited, tool to modelling spatial decision-making processes.

\section{References}

Barron, F, H. 1977: Axiomatic conjoint measurement. Decision Sciences, Vol. 8, pp. 48-59.

Emery, D. R., and Barron, F, H. 1979: Axiomatic and numerical conjoint measurement: An evaluation of diagnostic efficiency. Psychometrika, Vol. 44, pp. 195-211.

Girt, J. L. 1976: Some extensions to Rushton's spatial preference scaling model. Geographical Analysis, Vol. 8, pp. 137-156.

Green, P. E. 1974: On the design of choice experiments involving multifactor alternatives. Journal of Consumer Research, Vol. 1, pp. 61-68.

Johnson, $R$. M. 1974: Trade-off analysis of consumer values. Journal of Marketing Research, Vol. 11, pp. 121-127.

Krantz, D. H. 1964: Conjoint measurement: The Luce-Tukey axiomatization and some extensions. Journal of $\mathrm{Ma}$ thematical Psychology, Vol. 1, pp. 248-277.

Krantz, D. H., and Tversky, A, 1971: Conjoint measurement analysis of composition rules in psychology. Psychological Review, Vol. 78, pp. 151-169.

Lieber, $S$. $R$. 1979: An experimental approach for the migration decision process. Tijdschrift voor Economische en Sociale Geografie, Vol. 70, pp. 75-85.

Louviere, J. J. 1976: Information Processing Theory and Functional Measurement in Spatial Behavior, in R. G. Golledge and G. Rushton (eds). Spatial Choice and Spatial Behavior. Ohio State University Press, Columbus.

- 1979: Applications of Functional Measurement to Problems in Spatial Decision Making, in R. G. Golledge (ed.), Analysis of Spatial Behavioural Data. University of Minnesota Press, Minnesota.

- 1981: On the Identification of the Functional Form of the
Utility Expression and its Relationship to Discrete Choice, in D. A. Hensher and L. W. Johnson: Applied Discrete Choice Modelling. Halstead Press, London.

Louviere, J. J. and Meyer, R.J. 1979: Behavioral Analysis of Destination Choice, Technical Report 112. Institute of Urban and Regional Research, University of Iowa, Iowa City.

Louviere, J. J. and Wilson, E. 1978: Predicting consumer response in travel analysis. Transportation, Planning and Technology, Vol. 4, pp. 1-9.

Luce, R. D. and Tukey, J.W. 1964: Simultaneous conjoint measurement: $A$ new type of fundamental measurement. Journal of Mathematical Psychology, Vol. 1, pp. 1-27.

MacLennan, D. and Williams, N. J. 1979: Revealed space preference theory: A cautionary note. Tijdschrift voor Economische en Sociale Geografie, Vol. 70, pp. 307-309.

- 1980: Revealed preference theory and spatial choices: Some limitations. Environment and Planning A, Vol. 12, pp. 909-919.

Recker, W. and Kostyniuk, L. 1978: Factors influencing destination choice for the urban grocery trip. Transportation, Vol. 7, pp. 19-33.

Roskam, E. E. 1974: Unidimensional Conjoint Measurement (UNICON) for Multifaceted Designs. Psychologisch Laboratorium University of Nijmegen.

Rushton, G. 1969: Analysis of spatial behavior by revealed space preference. Annals of the Association of American Geographers, Vol. 59, pp. 391-400.

- 1969b: The Scaling of Locational Preference, in Cox, K. and Gollegde, R. G. (eds.) Behavioral Problems in Geography. Studies in Geography Northwestern University, Dept. of Geography, Evanston, Illinois.

Schuler, H. J. and Prosperi, D. C. 1978: A conjoint measurement model of consumer spatial behaviour. Regional Sci31, pp. 146-156.

Schuler, H.J. and Prosperi, D. C. 978: A conjoint measurement model of consumer spatial behavior. Regional Science Perspectives, Vol. 8, pp. 122-134.

Smith, A. P., Whitehead, P. J. and Mackett, R. L. 1977: The Utilization of Services, in Wilson, A. G., Rees, P. and Leigh, C. (eds.), Models of Cities and Regions. John Wiley, New York.

Srinivasan, V. and Shocker, A. D. 1973a: Linear programming techniques for multidimensional analysis of preferences. Psychometrika, Vol. 38, pp. 337-369.

- 1973b: Estimating the weights for multiple attributes in a composite criterion using pairwise judgments. Psychometrika, Vol. 38, pp. 473-493.

Timmermans, $H$. J. P. 1980: Unidimensional conjoint measurement models and consumer decision-making. Area, Vol. 12, pp. 291-300.

- 1981: Spatial choice behaviour in different environmental settings: An application of the revealed preference approach. Geografiska Antaler B., Vol. 63, pp. 57-67.

- 1982: Consumer choice of shopping centres: An information integration approach. Regional Studies, Vol. 16, pp. 171-183.

Timmermans, H. J. P., Heijden, R. van der, and Westerveld, $H$. 1982: The identification of factors influencing destination choice: An application of the repertory grid methodology. Transportation, Vol. 11, pp. 189-203.

- 1983: Conjoint measurement of individual preference functions: Some tests of validity, Area, Vol, 15 , pp. 245-250.

Tyersky, A. 1\%7: A general theory of polynomial conjoint measurement. Journal of Mathematical Psychology, $\mathrm{Vol}$. 4, pp. $1-20$. 